\title{
Análisis
}

\section{8: ¿Diarios en dispositivos móviles? Libro electrónico, tinta electrónica y convergencia de la prensa impresa y digital}

\author{
Por Javier Díaz-Noci
}

\begin{abstract}
Resumen: El camino hacia la completa digitalización y sustitución de la prensa en papel se está ya produciendo. La inminente comercialización de dispositivos móviles que emplean la tinta electrónica como el iLiad, de una empresa subsidiaria de Philips y, sobre todo, el nuevo modelo del Portable Reader System de Sony en España, con una decidida apuesta comercial, así como una incipiente investigación por parte de algunos diarios españoles, vuelve a plantear el interrogante de si el papel impreso está al final de su historia. Por el momento, estas novedades suponen un avance respecto a la situación precedente, pero aún hay demasiados inconvenientes que nos hacen dudar de que se trate sólo del principio de la recta final. La pujanza de otros dispositivos móviles, como los teléfonos de última generación (el iPhone de Apple) o la apuesta por el Kindle de Amazon, aún no comercializado en España, augura una interesante época de competencia y convergencia de formatos.
\end{abstract}

Palabras clave: Libro electrónico, Prensa digital, Tinta electrónica, Convergencia.

Title: 2018: Newspapers for mobile devices? E-book, E-ink and convergence of online and printed press

Abstract: The pathway to the complete digitisation and substitution of printed press is now a reality. The imminent commercialisation of new mobile devices using e-ink, licensed by Philips, and especially the new model of Sony's Portable Reader System in Spain (announced for Spring 2009), a determined commercial strategy, and incipient research by some Spanish newspapers make us wonder whether we are facing the end of the printed press. At the moment, the new devices are much better than their predecessors, but enough problems remain to make us doubt that we are at the beginning of the end of newsprint. The strengths of some other devices that differ from the e-book but could eventually be able to present books or newspaper on their screens, such as iPhone-like cell phones or Amazon's Kindle (not yet available in Spain) opens an interesting era of competition and convergence.

Keywords: E-book, E-ink, Digital press, Convergence.

Díaz-Noci, Javier. “2018: ¿Diarios en dispositivos móviles? Libro electrónico, tinta elec-

trónica y convergencia de la prensa impresa y digital”. El profesional de la información, 2009, mayo-junio, v. 18, n. 3 , pp. 301-307.

DOI: 10.3145/epi.2009.may.07

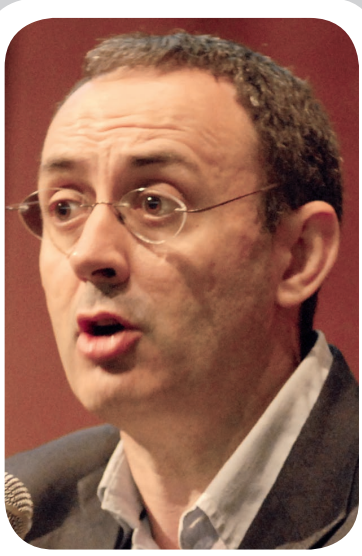

Javier Díaz-Noci es profesor titular de universidad. Ha sido docente en la Universidad del País Vasco y la Universitat Pompeu Fabra de Barcelona, y profesor visitante de las Universidades de Oxford (Reino Unido) y Federal de Bahía (Brasil). Autor de diversos libros y artículos sobre ciberperiodismo, ha coordinado una red hispano-brasileña de cooperación sobre comparación de medios digitales de ambos países, y ha participado en numerosas investigaciones sobre la cuestión.

\section{La muerte del papel, ¿una realidad?}

DESDE QUE, ALLÁ POR 1994-1995, apareciesen los primeros diarios en la World Wide Web, una pregunta recurrente por parte, sobre todo de los editores de prensa, es si "esto matará aquello"'.

La pregunta ha tratado de ser evitada por los que, como quien firma este texto, somos profesores de periodismo y nos dedicamos al estudio del ciberperiodismo, o periodismo en (por ahora) internet. Medida cautelar por si el debate se situaba donde, a nuestro entender, no debía: nos parecía y nos parece más importante estudiar los cambios que introduce la edición digital en el ejercicio de la profesión de informador, y en las empresas que hacen de ofrecer al público infor- 


\section{“¿Se producirá alguna vez la sustitución definitiva del papel por la pantalla, del libro por el libro electrónico, y de la prensa impresa por la prensa digital?"}

es si se producirá alguna vez la sustitución definitiva del papel por la pantalla, del libro por el libro electrónico, y de la prensa impresa por la prensa digital.

En las últimas décadas, un tema recurrente ha sido la comercialización de dispositivos de lectura digitales, bien dedicados exclusivamente a ello (los llamados e-books), bien otros entre cuyas funciones se incluye la de hacer funcionar, además de otro software diverso, programas que permitan la lectura de textos digitales, como las diferentes versiones del Acrobat Reader de Adobe para PC, Macintosh, pda u otros ordenadores. A ello hay que sumar la convergencia de diferentes funciones en un mismo aparato, el teléfono móvil especialmente, que convierten a estos últimos dispositivos en soportes de lectura de todo tipo de información multimedia: música, vídeo y, también, texto. La llegada del iPhone de Apple (con su estrategia no sólo novedosa en lo técnico, también y sobre todo en lo comercial) ha creado escuela, y cada vez son más los teléfonos móviles con una pantalla de tamaño generoso, que caben en la palma de la mano, que son susceptibles de ser cargados de aplicaciones para todo tipo de funciones (desde la geolocalización a los videojuegos, pasando por la lectura de libros), que son naturalmente móviles, y que permiten la conexión a internet, bien por vía telefónica, bien mediante wifi.

En este panorama, se están sumando decididamente otras tecnologías que se anunciaban hace casi una década. Una de ellas es la tinta electrónica, que, mediante una combinación de bolas microscópicas blancas y negras que se ordenan según impulsos eléctricos, nos proporciona la posibilidad de ver las páginas con sólo apretar un botón. $\mathrm{El}$ aspecto, se dice, es prácticamente el del papel, si bien de momento no es posible el color. El consumo de energía es reducido, porque las pantallas no son luminosas, al contrario de lo que ocurre con las de los ordenadores, pda o teléfonos móviles, y sólo precisan recurrir a la batería cuando se produce el cambio de página. Por lo tanto, la portabilidad es elevada. Así mismo, algunos dispositivos posibilitan la conexión a internet. Y, por último, la capacidad de memoria y almacenamiento es grande, y puede ser aumentada mediante slots de expansión.

\section{"Las grandes cabeceras americanas han apostado por ofrecer una edición para Kindle"}

A ello hay que sumar otro aspecto: la decidida campaña comercial de compañías como Amazon $\mathrm{o}$, a un nivel mundial mayor, la poderosa Sony. Precisamente, en la primavera de 2009 se anuncia la comercialización en España de los Portable Readers de esta empresa, a un precio muy competitivo que rondaría los 300 euros. Ya hay otros dispositivos a la venta, con una pantalla mayor, mejores prestaciones y, puede que ahí esté el quid de la cuestión, un precio que dobla al de la compañía japonesa.

La estrategia comercial presenta estos dispositivos como el equivalente para la lectura de lo que fueron los reproductores mp3 (con el glamouroso iPod de Apple a la cabeza) para la música: un medio de tener la información que nos agrada almacenada y dispuesta para ser recuperada en cualquier momento y lugar. La gran pregunta es si los libros electrónicos, tal y como se nos presentan ahora, son el final de algo o el principio de lo que podría ser la recta final del papel como soporte rey de la información textual y gráfica.

La pregunta que nos planteamos es hasta qué punto eso va a afectar a la industria no ya editorial del libro (eso fue investigado de forma inmejorable en varios artículos del v. 17, n. 4 de julio/agosto de 2008 de esta misma revista, El profesional de la información), sino a la de los editores de prensa. Algunos indicios que expondremos nos hacen pensar que, a pesar de todo, algo se mueve.

\section{8}

En la Feria Internacional del Libro de Frankfurt (Alemania) de 2008, una de las grandes noticias, o al menos como tal la presentó la prensa (sí, la prensa) fue la emergencia de los libros electrónicos. Estos dispositivos habían comenzado a ser tenidos en cuenta por los editores y preguntas como la gestión de los derechos digitales de las obras de los autores se hacían en voz cada vez más alta. La afición por las predicciones en forma de fecha exacta se dieron cita también en Frankfurt: 2018 será el año en que el volumen de negocio del libro digital superará al del libro impreso. Será entonces cuando el libro electrónico comenzará realmente a tomar el lugar del libro impreso.

Este tipo de predicciones son muy habituales; Bill Gates ha pronosticado sucesivamente la muerte de la prensa (en su libro de 1996 Camino al futuro), del CD, en 2004, y del teléfono fijo. Philip Meyer, prestigioso profesor de periodismo estadounidense, auguró en su libro The vanishing newspaper que la prensa impresa daría sus últimos estertores en 2043. 
La presentación, a principios de 2009, de la segunda versión del dispositivo de tinta electrónica Kindle, de la librería virtual Amazon, llevó a insistir en las predicciones: 2018, aseguraban diarios como El país, será el año en que "el viejo formato que lleva siglos haciendo las delicias de los lectores habrá sido sustituido en volumen de negocio por su rival electrónico". Kindle 2 , un dispositivo con teclado, que permite subrayar, tomar apuntes, o regular la intensidad de la iluminación, puede mostrar los contenidos de varios diarios, la mayoría de los Estados Unidos, y algunos internacionales, con cabeceras tan prestigiosas como Le monde, The times o el Frankfurter allgemeine, a un precio de entre 6 y 15 dólares americanos. Proporciona, además, una serie de revistas, algo más de una veintena, algunas del mundo impreso (como New yorker) y otras del digital (Slate). Las grandes cabeceras americanas, en su inevitable estrategia multiplataforma, han apostado por presentar una edición para Kindle. El dispositivo cuesta unos 350 dólares. El precio, por lo tanto, podría ser un factor determinante, y la apuesta por un coste rápidamente amortizable en cuanto se lean unos cuantos libros electrónicos es la que ha seguido también Sony.

Sony ha lanzado varios dispositivos de libro electrónico a lo largo de su historia, pero es con los dos últimos, que incorporan tecnología de tinta electrónica, cuando claramente intenta hacerse con una parte del mercado. El último de estos modelos, con pantalla algo más grande que la de su predecesor, que no llegaba a las medidas del A4, es el PRS-700BC. Sony, como Amazon, no comercializa su dispositivo en todos los países del mundo, sino que ha ido lanzándolo en diferentes mercados nacionales, primero en los Estados Unidos, luego en varios países de Europa. Tras haber sido lanzado en 2008 en Reino Unido y Francia, se anuncia en el primer
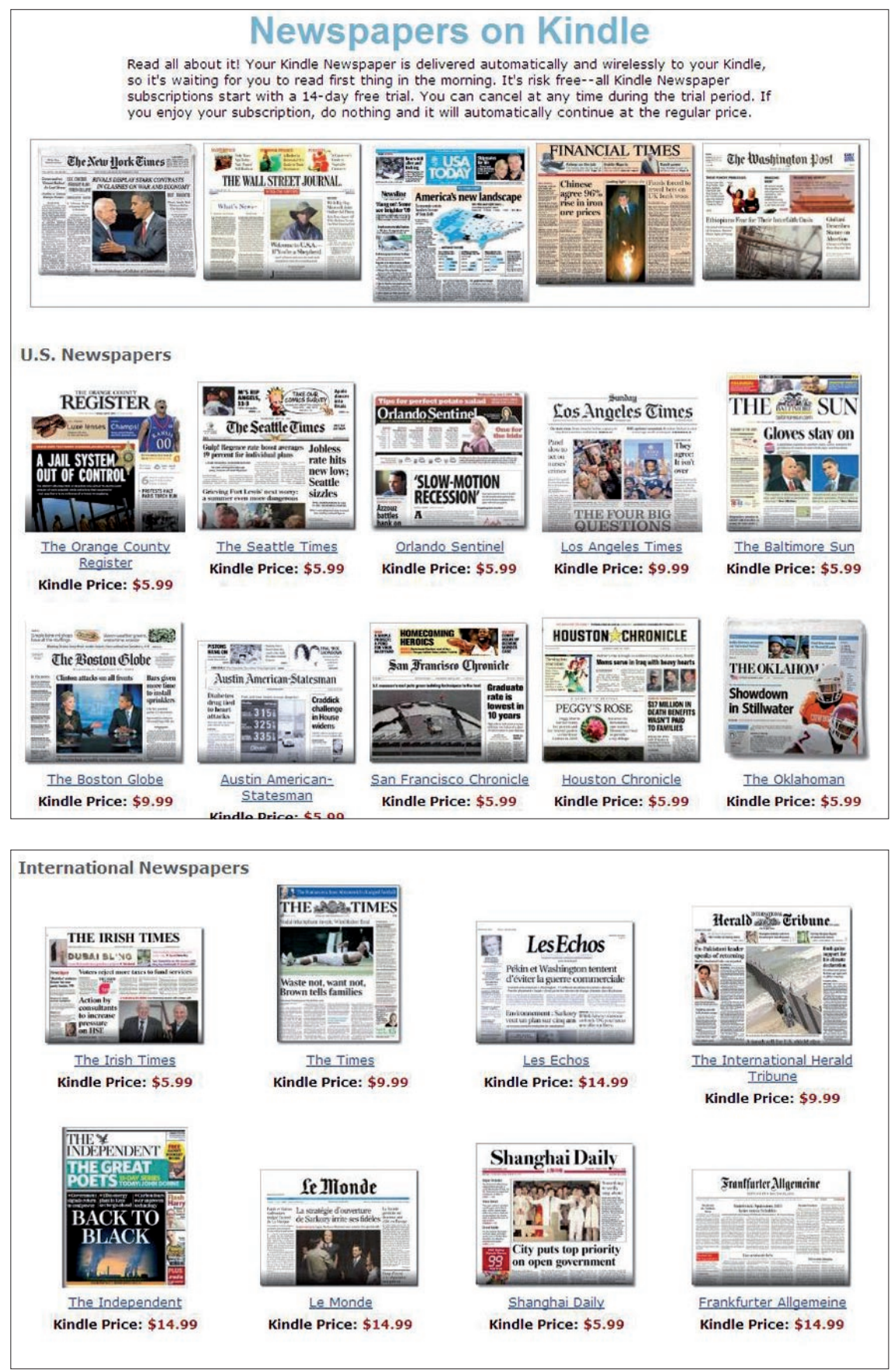

Diarios estadounidenses e internacionales que proporciona Amazon para Kindle 2

semestre de 2009 su comercialización en algunos establecimientos de firmas multinacionales en España. La pantalla es de 6 pulgadas y ya no sacrifica algunas prestaciones de las que sí carecía su precedente: la pantalla es táctil, por ejemplo, y lleva una pequeña luz (como Kindle 2 ; recordemos que se trata de pantallas no luminosas por sí mismas). La conectividad es muy limitada al no disponer de conexión wifi, con lo cual la dependencia de otros aparatos es manifiesta.

\section{"Hay que ver esta tecnología como una convergencia entre el diario impreso y el diario digital"} otros dispositivos que, de forma tímida, ya pueden encontrarse en algunas librerías de España, a un precio que ronda los 600 euros. El que
Hay, como ya hemos dicho, 
ha conseguido alguna fortuna es el iRex Iliad. La pantalla es sensiblemente mayor ( 8,1 pulgadas), es táctil y permite tomar notas e incluso escribir, pues incorpora un puntero $\mathrm{y}$ un sistema de reconocimiento de escritura manual. Los pocos diarios españoles que, al menos que sepamos, han hecho algún tipo de investigaciones con estos soportes, se han decantado por este modelo. Así, entre finales de 2008 y principios de 2009, Diario de Navarra ofrecía a sus lectores la posibilidad de adquirir a un precio más reducido la segunda versión de dicho aparato. Se trataba de una promoción como parte de una investigación de mercado. Se ofrecía una suscripción gratuita al diario, el iRex Iliad a mitad de precio (300 euros), 150 libros clásicos en versión electrónica y, a cambio, se pedía que se cumplimentasen tres formularios electrónicos en un plazo de cuatro meses. Iliad, al contrario que el dispositivo de Sony, dispone de conexiones wifi y ethernet. A pesar de todas sus limitaciones, y gracias seguramente al valor de marca y a su precio altamente competitivo, Sony ha conseguido vender más de 300.000 unidades desde el lanzamiento de su primer modelo, en octubre de 2006 (Coutinho, 2008).

Paralelamente, el citado rotativo estaba trabajando en el prototipo de una edición para el libro electrónico, con alguna hipertextualidad más bien reducida. El aspecto de los primeros prototipos, a finales de 2008, era más pobre que el de la edición para la www.

Otros diarios que también se habían planteado investigar en este terreno, como El segre, detuvieron sus intentos en 2008 a la espera de una coyuntura económica más favorable ${ }^{4}$.

\section{Algo de historia}

La iniciativa no es, sin embargo, tan novedosa. En los inicios del ciberperiodismo, se produjeron algu- nas investigaciones, con resultados diferentes, acerca de la posibilidad de presentar la información en una pantalla plana y portátil. Es lo que Roger Fidler, entonces en Knight Ridder, denominó flat panel. En 1996 escríbiamos (Díaz Noci et al., 1996) la siguiente descripción de ese dispositivo:

"Se trata de una tableta de unos veinte por treinta centímetros, con un espesor de aproximadamente un centímetro, cerca de un kilogramo de peso, que se pensaba haber lanzado al mercado en 1996. Esta tableta plana debía permitir tanto la conexión en línea, vía terrestre, como vía aérea, y junto con la lectura del periódico electrónico multimedia e interactivo, debía permitir además realizar operaciones bancarias, reservas de billetes de avión, cine y espectáculos, lectura y envío del correo electrónico o videojuegos a distancia. La interacción habría de producirse mediante un lápiz electrónico, por contacto sobre una pantalla de alta definición, similar a la del papel, o mediante la palabra, una vez que la tecnología de reconocimiento de voz fuese posible y efectiva. La clave estaba en la portabilidad, lo que le permitiría ser una verdadera alternativa al periódico impreso, la facilidad de uso y unas prestaciones mejores que las del diario tradicional".

El dispositivo nunca se convirtió en realidad. El proyecto fue cancelado en julio de 1995.

Sí lo hizo, en cambio, el NewsPad de El periódico de Catalunya (Molina, 1999), en 1996. Fue fruto de una investigación comenzada en marzo de 1994, subvencionada por la Unión Europea y en la que participaron Acorn Computer, $\mathrm{Ca}$ rat, la Universidad de Edimburgo, el Institut Català de Tecnologia y otras empresas y entidades. Se llegó a construir un prototipo operativo que funcionaba. La idea era que el periódico actualizado se pudiese cargar en el NewsPad en cualquier momento del día. Se pensó en una disposición de las noticias que hoy parecería inocente, pero que en su día suponía no ceñirse necesariamente al diseño de la prensa impresa: un carrusel superior de noticias.

Mario Santinoli, responsable del proyecto y a la sazón director técnico de El periódico de Catalun-

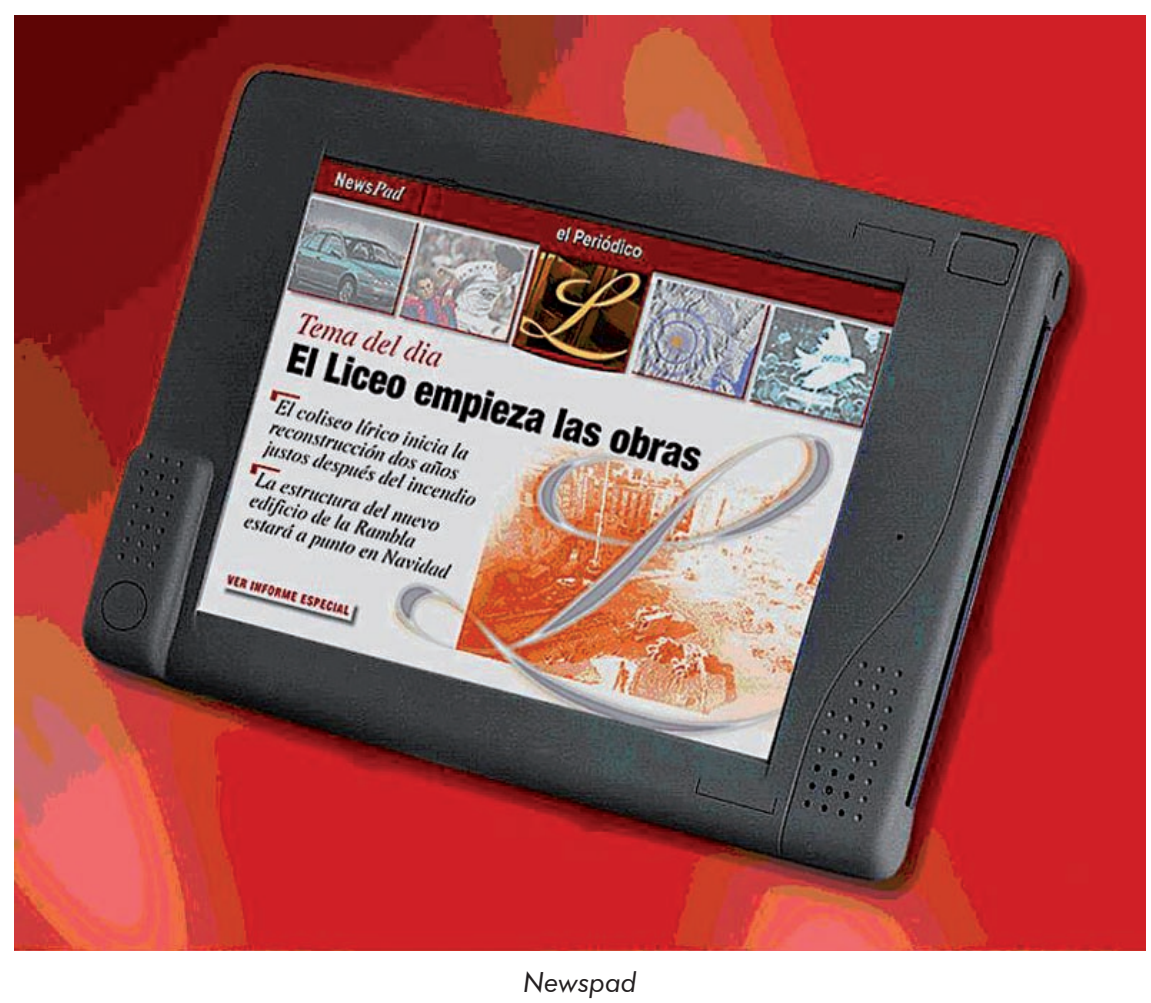


ya, definía el Newspad como una tableta de bolsillo que recibiría la información vía satélite o mediante redes, y utilizaría todo el potencial multimedia posible para hacer la navegación por la información mucho más intuitiva. Ese planteamiento no ha dejado de ser actualidad, casi quince años después.

Curiosamente, tal y como recogíamos en nuestro libro de $1996 \mathrm{El}$ periodismo electrónico, "según los planes comerciales, se prevé que su desarrollo comercial se producirá entre los años 2002 y 2005, si bien habrá que esperar hasta el 2010 para que se extienda en el mercado de manera masiva". Sólo muy pocos años después de la fecha anunciada, nos encontramos con un cierto resurgimiento de las preguntas de antaño.

\section{¿La definitiva implantación del papel y la tinta electrónicos?}

En aquellos tiempos de mediados de los años 90, algunas otras ideas visionarias se apuntaban como posibles, aunque lejanas: el papel electrónico que desarrollaban Xerox y $3 M$ (Gyricon), que se hizo realidad en 1999 (aunque la idea empezó a fraguarse en 1978 en los laboratorios de Palo Alto) o el ordenador en papel, que costaría apenas unos dólares y sería desechable, de un tal Jim Willard, del que nunca se ha vuelto a hablar, o aquel otro prototipo en el que trabajaba $I B M$ y que sobre todo, se creía, serviría para los diarios electrónicos.

Finalmente, la empresa que más ha apostado por la tinta electrónica ha sido E-Ink Corporation, que es la que suministra la tecnología a los dispositivos que hemos examinado, especialmente el Sony Reader y el iRex Iliad.

En cuanto a los diarios, los movimientos, aunque sean todavía tímidos, por acercarse a la edición para e-book comienzan en 2006: "Moving newspapers to e-ink has

\section{"La definitiva implantación y mejora de esta tecnología permitiría explotar también las hemerotecas históricas"}

already begun", decía Ryan Block: "De Tijd, a Belgian financial newspaper, has already put their paper on iLiad e-ink e-book readers; Les echos in Paris, the IFRA group in Germany, The New York times, as well as the International herald tribune are all in discussions to roll out e-newspaper subscriptions for devices like Sony's Reader later this year". El belga De Tijd puede ser considerado, efectivamente, el primer diario europeo en investigar este campo. Ese mismo año de 2006, el propio New York times recogía seriamente esas investigaciones de sus colegas y se hacía eco de la posibilidad de un futuro no muy lejano en que los diarios se pareciesen a los que se leían en el metro en el film de Steven Spielberg, Minority report. A ese grupo de diarios se les unió en 2008 el holandés NRC Handelsblad, con una edición para el iRex Iliad. También en 2008, Newsweek ya especulaba seriamente con un "no-paper newspaper", si bien lo contemplaba con (todavía) una considerable dosis de escepticismo.

http://www.engadget.com/2006/ 04/24/moving-newspapers-to-eink-has-already-begun/

Una vez consolidada la tecnología de la tinta electrónica en Europa, se han llevado a cabo algunas investigaciones técnicas y de mercado, como las que han realizado UniNews y DigiMedia (Ihlström, 2007). La opinión de los que probaron esos dispositivos con diarios digitales fue más positiva de lo esperado, a pesar de sus muchas limitaciones. Durante 2008 se ha llevado a cabo un segundo análisis más profundo con cinco diarios suecos y 50 familias de ese país escandinavo, uno de los de más alto índice de lectura del continente. Otra conclusión del estudio de Carina Ihlström nos parece aún más interesante: más que ver esta tecnología como sustitutoria del diario impreso, habría que verla como una convergencia entre éste y el diario digital.

La definitiva implantación y mejora de esta tecnología, y su uso masivo por parte de los usuarios, permitiría explotar no sólo las ediciones actuales, sino también las hemerotecas históricas. Cada vez son más las empresas que llevan a cabo un facsímil (generalmente, en pdf) de sus hemerotecas, en algunos casos (como La vanguardia), centenarias. En otros casos, son instituciones (la pionera fue la Bodleian Library de Oxford, con el proyecto ILEJ: Internet library of early journals). Se les han sumado otros: empresas como Google se han hecho con el ambicioso empeño de digitalizar todos los libros, y probablemente las publicaciones periódicas, del mundo. $\mathrm{Si}$, como asegura el editorial de El país del 11 de febrero de 2009, todo lo que existe podrá leerse en estos dispositivos, "y los nuevos soportes electrónicos son la solución definitiva para tantos males asociados al papel y para acabar con la mayor de sus despóticas exigencias: el espacio", las estrategias de digitalización de su archivo hemerográfico deberían ser una prioridad para las empresas editoras de prensa. Para ese empeño facsimilar, el pdf se ha convertido en el estándar técnico preferido, si bien pocas empresas periodísticas han hecho uso de todas sus posibilidades (Voces; Codina, 2008). La imposibilidad de buscar mediante texto libre por esa inmensa masa de información (es el problema de la hemeroteca histórica de La vanguardia, por ejemplo) es un reto a ser superado. Sin embargo, ya hay otros formatos y estándares que vendrían a complementar al pdf; 
Adobe ha lanzado el formato epub, más flexible y líquido, que se adapta mejor a dispositivos como los de Sony, con problemas para mostrar adecuadamente y sin romper el diseño los documentos pdf al ampliarlos.

Roger Fidler vuelve a la carga: en los Nieman Reports de la fundación de igual nombre para el estudio del periodismo de la Universidad Harvard abogaba por volver a experimentar con estos dispositivos móviles e insistía en combinar lo mejor del nuevo y el viejo mundo: facilidad de uso (curva de aprendizaje corta), color, portabilidad (ligero y delgado), con una legibilidad como la del papel, donde se puedan tomar notas, que pueda presentar todo tipo de información (textual, sonora, visual, infografías) y con una batería de larga duración.

Habría que añadir algunas particularidades más, que ya están al alcance del usuario en otros dispositivos como los teléfonos móviles de última generación (como el $i$ Phone): una pantalla táctil (ésa parece ser la interfaz más efectiva hoy en día, y la preferida por los usuarios), altamente conectado (con posibilidad de transferencia de archivos mediante bluetooth, wifi o cable USB a otros dispositivos: ordenadores, teléfonos móviles, agendas electrónicas, etc.) y conectados a otros usuarios y a la Web. En definitiva, lo que imagina Nancy K. Herther para el e-book del futuro.

Hay algunos pequeños pasos: en abril de 2008, la compañía de telefonía móvil francesa Orange (que también opera en otros países, como España) lanzó el Read \& Go, un terminal 3-G con tecnología $e$ paper en el que ofrecía la lectura de cinco diarios franceses: Le monde, Le parisien, Les echos, L'equipe y Télérama. Se le denominó "kiosco electrónico", y de hecho era una respuesta a la estrategia del Kindle de Amazon. Usa el dispositivo iRex Iliad y permite descargarse las ac-

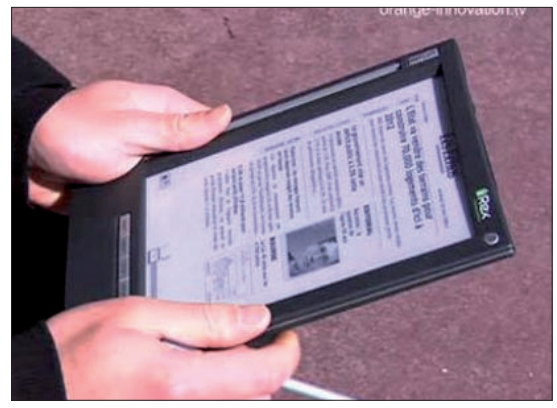

El kiosco digital de Orange

tualizaciones que cada hora hacen estos diarios para el $e$-reader.

Y hay más experimentos en marcha: la empresa Plastic Logic está trabajando en un dispositivo aún más plano, y con una pantalla mayor que sus competidores, dirigido a la lectura de diarios digitales. En febrero de 2009, esta compañía, USA today y el Financial times firmaron un acuerdo para que las dos últimas desarrollen contenidos, según anunciaba la revista profesional Editor \& publisher. El dispositivo se comercializaría en 2010, tras un período de pruebas con usuarios en el segundo semestre de 2009.

http://www.editorandpublisher. com/eandp/departments/business/ article_display.jsp?vnu_content_ id $=1003939809$
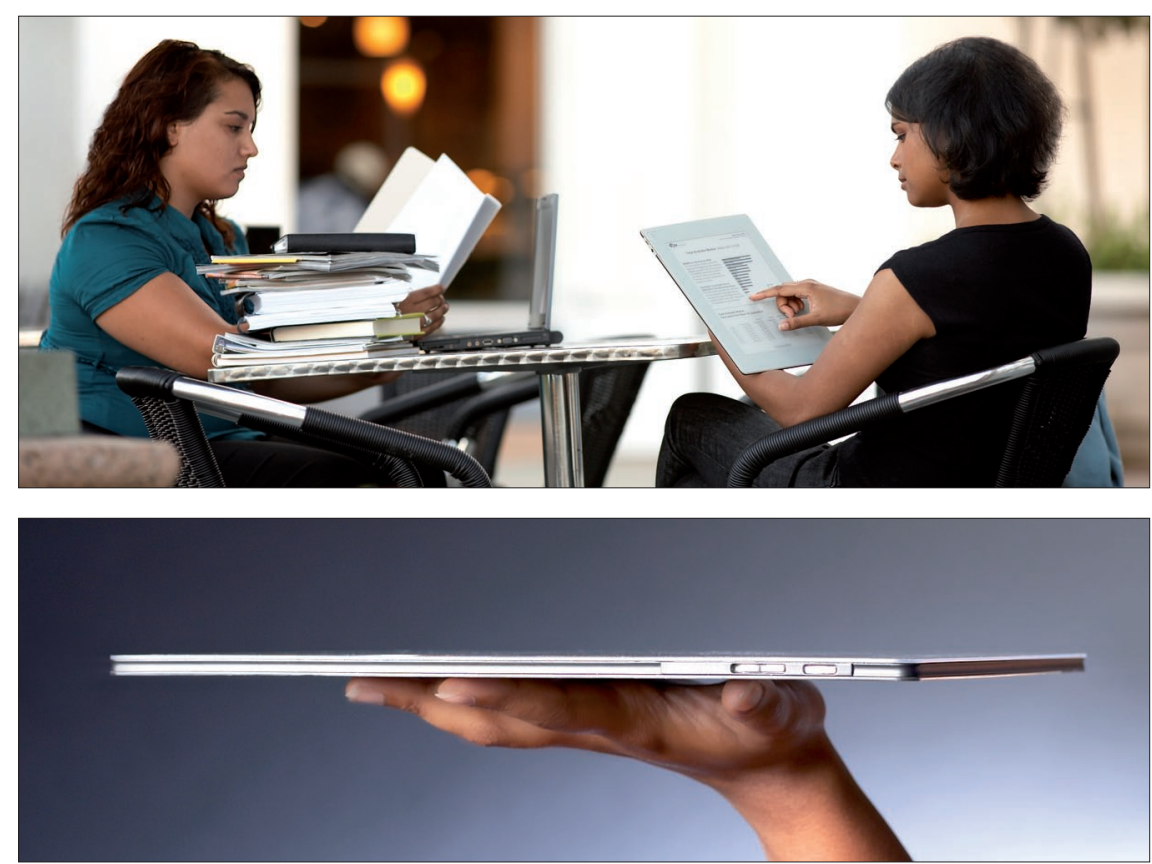

El futuro dispositivo de Plastic Logic, según dos imágenes tomadas de la web de la compañía http://www.plasticlogic.com/product.html vergencia de formatos $\mathrm{y}$, sobre todo, en la posibilidad de tener lo mejor de la experiencia de los diferentes medios de comunicación accesible en varios tipos de dispositivos. La concepción del diario como una base de datos dinámica que permita (como decía Nicholas Negroponte en su Being digital) un diario personalizado, un daily me, se intuye cada vez más cercano. De momento, sin embargo, y aunque ya se ven en el metro algunas personas leyendo en su e-book, parece aún un tanto lejano (pero no imposible) el día en que el periódico sea como lo imaginaron los asesores de Spielberg.

\section{Notas}

1. Por cierto, el título de un libro con posfacio de Umberto Eco y coordinado por Geoffrey NunBarcelona: Paidós, 1998.

2. Díaz-Noci, Javier; Meso Ayerdi, Koldo. "Desarrollo del periodismo electrónico". El profesional de la información, v. 7, n. 12, diciembre 1998, pp. 4-11.

3. Domingo, David; Paterson, Chris. Making online news. The ethnography of new media production. New York, etc.: Peter Lang, 2008.

4. Pere Masip, en el blog Infotendencias explicaba en mayo de 2008 que "para este proyecto Segre usará la aplicación Milenium E-paper creada por la empresa española Protec. A diferencia de lo que ocurre con otras tecnologías e-paper, que fundamentalmente no hacen más que generar berg: El futuro del libro. ¿Esto matará aquello? 
una imagen de visualización, Milenium trabaja por contenidos, lo que permite que sea el propio periodista que elabora los contenidos quien decida si éstos van a ir al papel, a la web, al e-paper o a los tres. Del mismo modo, el periodista puede incorporar nuevos recursos (imágenes, enlaces, elementos multimedia), con lo que, según indica el director técnico de Segre, Ferran Perdrix, se mejoran los contenidos editoriales y se aporta valor añadido al formato papel". Masip seguía una noticia de Ifra.

http://infotendencias.com/2008/05/14/el-diariosegre-anuncia-la-aparicion-del-periodico-enformato-e-paper/

http://www.ifra.com/website/news.nsf/wuis/A8C 5918A4BC6EDDCC125744100324281?OpenD ocument \& $0 \& E \&$

\section{Bibliografía}

Arquero-Avilés, Rosario; García-OchoaRoldán, María-Luisa. La hemeroteca de prensa. Gijón: Ediciones Trea, 2005.

"De cabeza al libro electrónico". El país, 11 de febrero de 2009, p. 24.

Busa, Roberto A. "Foreword: perspectives on the digital humanities". En: Schreibman, Susan; Siemens, Rayu; Unsworth, John (eds.). A companion to digital humanities. Oxford: Blackwell, 2004. http://www.digitalhumanities.org/companion/
Carvajal, Doreen. "One day soon, straphangers may turn pages with a button". New York times, 24 de abril de 2006

http:// www.nytimes.com/2006/04/24/business/ media/24epaper.html

Coutinho, Isabel. "E-books em consolas e telemóveis". Público, 12 de diciembre de 2008, p. 36.

Díaz-Noci, Javier; Meso-Ayerdi, Koldo; Ar mañanzas, Emiliana. El periodismo electrónico. Información y servicios en la era del ciberes pacio. Barcelona: Ariel, 1996.

Epub best practices guide. Version 1.0. [s. 1.] Adobe Digital Publishing Team, 2008.

http://www.adobe.com/devnet/digitalpublishing

Estudio Digitalización del libro en España. Madrid: Liber, 2008

Fidler, Roger. "Using e-readers to explore some new media myths". En: Nieman reports. Cambridge, MA: Harvard University, 2008.

http://www.nieman.harvard.edu/reportsitem. aspx?id=100686

Fidler, Roger. Mediamorphosis. Understanding new media. Thousand Oaks: Pine Forghe Press, 1997.

Herther, Nancy K. "The e-book reader is not the future of e-books". Searcher. The magazine for da tabase professionals, September 2008, pp. 26-40.
Ihlström, Carina. "Introducing the e-newspaper - Audience preferences and demands". En: Proc Elpub2007 Conf on Electronic Publishing, Vienna, Austria, June 2007 http://elpub.scix.net/data/works/att/102_ elpub2007.content.pdf

McGinn, Daniel. "A no-paper newspaper. After years of hype, 'e-newspapers' are getting closer to reality. Can they save a shrinking industry?" Newsweek, Sept. 6, 2008.

http://www.newsweek.com/id/157580

Molina, Alfonso. "Transforming visionary products into realities: constituency-building and observacting in NewsPad". Futures, 1999, n. 31, p. 291-332.

Voces-Merayo, Ramón; Codina, Lluís. "La accesibilidad potencial y real del formato pdf: análisis de diarios digitales españoles". El profesional de la información, v. 17, n. 2, marzoabril 2008.

\section{Javier Díaz-Noci}

Universitat Pompeu Fabra, Barce-

lona

javier.diaz@upf.edu

\section{Máster Oficial Universitario}

\section{Contenidos y Aspectos Legales en la Sociedad de la Información}

\section{Objetivos}

Especializar a profesionales de la información en la gestión de contenidos a través de diferentes plataformas para todos los ámbitos de la sociedad. Ahondar y ampliar los conocimientos en Archivística, Biblioteconomía y Documentación con un enfoque dirigido a la aplicación de las tecnologías de la información en sus nuevos canales. Temas centrales son los contenidos audiovisuales.

\section{Especialidades}

- Información y Documentación: Gestión de contenidos multicanal.

Gestión de contenidos en nuevos formatos y distribuidos por distintos canales. Web 2.0, Redes sociales y Conocimiento colaborativo.

- Archivos y administración electrónica.

Gestión de los documentos electrónicos y sistemas de gestión documental. Administración electrónica.

\section{Estructura del Máster}

75 ECTS a impartir en un curso académico.

Horario de tarde

Materias- 42,5 ECTS - se compone de asignaturas comunes y asignaturas de la especialidad que se escoja

Asignaturas de libre configuración curricular: 17,5 ECTS

Tesina fin de Máster: 15 ECTS

\section{Profesorado}

Este Máster será impartido por profesorado de diversas Universidades Nacionales así como profesionales de reconocido prestigio.

\section{Fechas}

Plazos de preinscripción:

Del 2 al 12 de Septiembre y del 1 al 8 de Octubre Plazos de Matrícula:

Del 23 al 30 de Septiembre

Del 20 al 24 de Octubre

\section{Información}

Secretaría del Departamento de Comunicación Audiovisual, Documentación e Historia del Arte (DCADHA) de la UPV.

Teléfono: 963877390

e-mail: dephar@upvnet.upv.es

Página Web:

http://www.upv.es/contenidos/PO/menu_494 351c.html

\section{Preinscripción}

http://www.upv.es/contenidos/PO/menu_49504 3c.html

Estos estudios dan acceso al programa de Doctorado

El master admite estudiantes titulados, tanto de nivel superior como de nivel medio (licenciados y diplomados

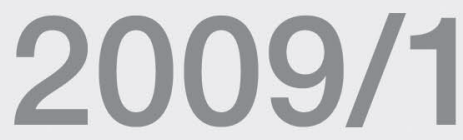

MINISTERIO
INSTITUTO

DE DISEÑO Y FABRICACIÓN 